\title{
Supercritical carbon dioxide extraction of bioactive flavonoid from strobilanthes crispus (Pecah Kaca)
}

\begin{abstract}
The bioactive flavonoid compounds of Strobilanthes crispus (Pecah Kaca) leaves obtained by using supercritical carbon dioxide (SC-CO2) extraction were investigated and the obtained crude extract yields were compared in order to select the best operation parameters. Since carbon dioxide is a non-polar solvent, ethanol was used as co-solvent to increase the polarity of the fluid. The studied parameters were pressure (100, 150 and 200 bar), temperature (40, 50 and $60{ }^{\circ} \mathrm{C}$ ) and dynamic extraction time (40,60 and $80 \mathrm{~min}$ ). The optimum extraction condition occurred at $200 \mathrm{bar}, 50{ }^{\circ} \mathrm{C}$ and $60 \mathrm{~min}$. Based on the mean value, pressure had dominant effect on the extraction yield. Apart from the optimum SFE conditions two other conditions namely at minimum (100 bar, $40{ }^{\circ} \mathrm{C}, 40 \mathrm{~min}$ ) and maximum (200 bar, $60{ }^{\circ} \mathrm{C}, 80$ min) levels of each studied parameters as control runs were analyzed by HPLC to determine the major bioactive flavonoid compounds from S. crispus. Under the optimum conditions eight flavonoid compounds were identified; they were (+)-catechin, (ī )-epicatechin, rutin, myricetin, luteolin, apigenin, naringenin and kaempferol.
\end{abstract}

Keyword: Strobilanthes crispus; Bioactive flavonoid; Supercritical carbon dioxide extraction; HPLC 